\title{
A Review on Medicinal Properties of Orientin
}

\author{
Kit Ying Lam, ${ }^{1}$ Anna Pick Kiong Ling, ${ }^{2}$ Rhun Yian Koh, ${ }^{2}$ \\ Ying Pei Wong, ${ }^{2}$ and Yee How Say ${ }^{3}$ \\ ${ }^{1}$ School of Postgraduate Studies and Research, International Medical University, 57000 Kuala Lumpur, Malaysia \\ ${ }^{2}$ Division of Biomedical Science and Biotechnology, School of Health Sciences, International Medical University, \\ 57000 Kuala Lumpur, Malaysia \\ ${ }^{3}$ Department of Biomedical Science, Faculty of Science, Universiti Tunku Abdul Rahman, Perak Campus, \\ 31900 Kampar, Perak, Malaysia
}

Correspondence should be addressed to Anna Pick Kiong Ling; anna_ling@imu.edu.my

Received 17 November 2015; Revised 4 March 2016; Accepted 14 April 2016

Academic Editor: Hansen Wang

Copyright (C) 2016 Kit Ying Lam et al. This is an open access article distributed under the Creative Commons Attribution License, which permits unrestricted use, distribution, and reproduction in any medium, provided the original work is properly cited.

Medicinal plants continue to play an important role in modern medications and healthcare as consumers generally believe that most of them cause fewer or milder adverse effects than the conventional modern medicines. In order to use the plants as a source of medicinal agents, the bioactive compounds are usually extracted from plants. Therefore, the extraction of bioactive compounds from medicinal plants is a crucial step in producing plant-derived drugs. One of the bioactive compounds isolable from medicinal plants, orientin, is often used in various bioactivity studies due to its extensive beneficial properties. The extraction of orientin in different medicinal plants and its medicinal properties, which include antioxidant, antiaging, antiviral, antibacterial, antiinflammation, vasodilatation and cardioprotective, radiation protective, neuroprotective, antidepressant-like, antiadipogenesis, and antinociceptive effects, are discussed in detail in this review.

\section{Introduction}

Plants have been the key source of medicinal agents since ancient times. Based on fossil records, the use of medicinal plants most likely began in the middle Paleolithic about 60,000 years ago [1]. Over the years, traditional medicinal plants have been widely used to treat and/or to prevent diseases and even for daily consumption. For example, Camellia sinensis is an evergreen tree whose leaves and leaf buds are used to produce tea. The hot water extract of the dried leaf is taken orally as an antihypertensive tea in China, but to increase milk production for nursing mothers in Mexico. Indians also use the powder or decoction of dried leaves on teeth to prevent tooth decay [2]. The other example is Gingko biloba, which has traditionally been used to improve memory. The Chinese take the oil from fruit pulp to treat pulmonary tuberculosis but consume the hot water extract of the leaf orally as a vermifuge and also to treat asthma and senility [3]. Besides that, Koreans use the hot water extract of the Gingko biloba seed to induce labour or as an abortifacient [3].
In addition, the Ocimum sanctum Linn. (holy basil) has been used for the treatment of malaria, dysentery, skin disease, arthritis, bronchitis, asthma, and verminosis in the ancient Indian system of medicine $[4,5]$.

Traditionally, all of or part of a therapeutic plant such as garlic and cranberry is used as an herbal remedy. However, this has evolved in the recent drug discovery processes, in which bioactive compounds were isolated from plants and used as drugs, either in its original or in semisynthetic form [6]. Normally, semisynthesis of novel bioactive compounds with higher therapeutic values and lower toxicity can be done by modifying the structure of the existing bioactive compounds [7]. With this development, medicinal plants, particularly those with less toxic secondary metabolites, continue to play an important role in the modern medication and healthcare. According to Prasad and Tyagi, about 61\% of 877 small-molecule drugs introduced worldwide between 1981 and 2002 were derived from natural products [8]. Some famous examples of plant-derived modern medicines are the cardiotonic drug (Digitoxin and Digoxin from Digitalis 
<smiles>[2H][C@@]1(c2c(O)cc(O)c3c(=O)cc(-c4ccc(O)c(O)c4)oc23)O[C@H](CO)[C@@H](O)[C@H](O)[C@H]1O</smiles>

FIGURE 1: Chemical structure of orientin.

purpurea L.) [6-8], the anti-inflammatory drug (Aescin from Aesculus hippocastanum L.) [7], antitumour agent (Etoposide from Podophyllum peltatum L. [7, 8], Vincristine and Vinblastine from Catharanthus roseus [6, 8], Irinotecan and Topotecan from Camptotheca acuminate [8], Paclitaxel and Abraxane from Taxus brevifolia [8], Solamargine from Solanum dulcamara [8], Masoprocol from Larrea tridentata [8], Alitretinoin from Daucus carota [8]), antimalaria and antiarrhythmic agent (quinine and quinidine from Cinchona spp.) [6], muscle relaxant (atropine from Atropa belladonna) [6], and antinociceptive and cough suppressant drugs (morphine and codeine, resp.) from Papaver somniferum [6].

Considering the importance of bioactive compounds, extraction of these bioactive compounds from medicinal plants is a crucial step in producing plant-derived drugs. One of the bioactive compounds isolable from medicinal plants, orientin, is often used in the studies due to its extensive therapeutic properties. Orientin is a water-soluble flavonoid $C$-glycoside, which is commonly extractable from some medicinal plants such as Ocimum sanctum (holy basil) [9-11], Phyllostachys nigra (bamboo leaves) [12-18], Passiflora species (passion flower) [19, 20], Trollius species (Golden Queen) [21-24], Jatropha gossypifolia (Bellyache Bush) [2528], Linum usitatissimum (flax) [29], Commelina communis (dayflower) [30], Euterpe oleracea Mart. (Acai palm) [31], Ascarina lucida [32], Celtis africana (white stinkwood) [33], Croton zambesicus (Lavender croton) leaves [34], Cajanus cajan (Pigeon pea) leaves [35], and Thlaspi arvense (Field Pennycress) [36]. The extraction of orientin in different medicinal plants and its medicinal properties, which include antioxidant, antiaging, antiviral, antibacterial, anti-inflammation, vasodilatation and cardioprotective, antiadipogenesis, antinociceptive, radiation protective, neuroprotective, and antidepressant-like effects, are discussed in this review.

\section{Orientin}

Orientin is a water-soluble flavonoid $C$-glycoside which has the IUPAC name of 2-(3,4-dihydroxyphenyl)-5,7-dihydrox-y-8-[(2S,3R,4R,5S,6R)-3,4,5-trihydroxy-6-(hydroxymethyl)oxan-2-yl]chromen-4-one. It has a molecular formula of $\mathrm{C}_{21} \mathrm{H}_{20} \mathrm{O}_{11}$ and a molecular weight of $448.3769 \mathrm{~g} / \mathrm{mol}$ [38]. The chemical structure of orientin (Figure 1) shows that it consists of mostly phenol groups with two ether groups and one ketone group. Therefore, a polar solvent such as methanol, ethanol, or water is required to extract orientin from the medicinal plants.

\section{From Plants to Orientin}

Orientin has been isolated from various medicinal plants such as Ocimum sanctum, Phyllostachys species (bamboo leaves), Passiflora species (passion flowers), Trollius species (Golden Queen), and Jatropha gossypifolia (Bellyache Bush).

Ocimum sanctum (also known as Indian holy basil or Tulsi in Sanskrit) was planted in India and it is well known for its medicinal values. The Ayurveda (Indian ancient system of medicines) uses different parts of Ocimum sanctum to treat cough, common cold, malarial fever, skin diseases, and snake bites [39]. Nair et al. successfully isolated orientin from the leaves of $O$. sanctum alongside with other flavonoids such as apigenin, apigenin-7-O-glucuronide, molludistin, luteolin, and luteolin-7-O-glucuronide [10]. Similarly, Uma Devi et al. isolated orientin from the same plant parts for in vivo radioprotective effect studies [11].

Bamboo leaves have been an essential resource in China for years and Phyllostachys pubescens Mazel ex H. de Lehaie is the most abundant species among the bamboo leaves in China due to its high yield, high growth rate, and extensive use [12]. Yong et al. isolated orientin and other compounds such as isoorientin, vitexin, isovitexin, caffeic acid, and ferulic acid by immersing different cultivars of $P$. pubescens in $70 \%$ methanol [16]. Besides that, Zhang et al. have isolated $49 \mathrm{mg}$ of orientin from the antioxidant of bamboo leaves (AOB) concentrated solution initially from the $6.5 \mathrm{~g}$ of crude column chromatography fraction [17]. In addition, orientin has been separated from the three bamboo species: Phyllostachys pubescens Mazel ex H. de Lehaie, Phyllostachys glauca McClure, and Pleioblastus yixingensis by Sun et al. with newly proposed high-performance thin-layer chromatography (HPTLC) method [18]. With this simple method, 6.44, 7.82 , and $4.92 \%(\mathrm{w} / \mathrm{w})$ of orientin were produced from $P$. pubescens, $P$. glauca, and P. yixingensis, respectively [18].

Orientin has also been isolated from the Passiflora species. Passiflora was originally named in Spanish meaning "the flower with the five wounds" in the 17th Century by Spanish priests in South America. Up to now, there are about 400 Passiflora species that have been recognised. It was suggested that Passiflora incarnata is used as a mild calming agent while other species were reported to possess medicinal properties [19]. In isolating orientin, Grundmann et al. managed to obtain $3.36 \mathrm{mg}$ of orientin per gram of dried $P$. incarnata [19] while de Paris et al. isolated orientin from water extract of $P$. edulis dried leaves [20].

In Traditional Chinese Medicine, Trollius chinensis Bunge has been used to treat pharyngitis, respiratory infections, bronchitis, and tonsillitis for years. The dried flowers of other Trollius species were also discovered to possess various medicinal properties [37]. Liu et al. used HPLC method to isolate orientin from Trollius chinensis with the detection wavelength of $340 \mathrm{~nm}$ [21]. Besides that, $5 \mathrm{mg}$ of orientin has been eluted from $15 \mathrm{~kg}$ of dried flowers of Trollius ledebouri 
TABLE 1: Isolation of orientin from different medicinal plants.

\begin{tabular}{|c|c|c|c|c|}
\hline Medicinal plants & Solvents & $\begin{array}{l}\text { Separation and analysis } \\
\text { methods }\end{array}$ & Amount of orientin extracted & References \\
\hline Ocimum sanctum & Water & $\begin{array}{l}\text { (i) Chromatography } \\
\text { (ii) NMR }\end{array}$ & - & {$[10-12]$} \\
\hline Phyllostachys species & Methanol or ethanol & $\begin{array}{l}\text { (i) Chromatography } \\
\text { (silica gel column or } \\
\text { AB-8 resin column) } \\
\text { (ii) HPLC } \\
\text { (iii) HPTLC }\end{array}$ & $\begin{array}{l}\text { (i) } 49 \text { mg of orientin from the AOB } \\
\text { concentrated solution } \\
\text { (ii) } 6.44 \%, 7.82 \% \text {, and } 4.92 \%(\mathrm{w} / \mathrm{w}) \\
\text { of orientin were produced from } P \text {. } \\
\text { pubescens, } P \text {. glauca, and } P \text {. } \\
\text { yixingensis, respectively, by HPTLC }\end{array}$ & {$[15-19]$} \\
\hline Passiflora species & Ethanol or water & $\begin{array}{l}\text { (i) TLC } \\
\text { (ii) HPLC }\end{array}$ & $\begin{array}{l}\text { (i) } 3.36 \mathrm{mg} \text { of orientin per gram of } \\
\text { dried P. incarnata extract }\end{array}$ & {$[21,37]$} \\
\hline Trollius species & Ethanol & $\begin{array}{l}\text { (i) HPLC } \\
\text { (ii) Column } \\
\text { chromatography } \\
\text { (iii) HSCCC } \\
\text { (iv) UPLC-ESI-MS/MS }\end{array}$ & $\begin{array}{l}\text { (i) } 5 \mathrm{mg} \text { of orientin from } 15 \mathrm{~kg} \text { of } T \text {. } \\
\text { ledebouri dried flowers } \\
\text { (ii) } 95.8 \mathrm{mg} \text { of orientin from } 500 \mathrm{mg} \\
\text { of the crude extract of T. ledebouri } \\
\text { (iii) Able to measure minimum } \\
515 \mu \mathrm{g} \text { of orientin per gram of plant } \\
\text { material by UPLC-ESI-MS/MS } \\
\text { method }\end{array}$ & {$[25-27]$} \\
\hline Jatropha gossypifolia & $\begin{array}{c}\text { Water, } \\
\text { dichloromethane, } \\
\text { ethyl acetate, } \\
\text { n-butanol, or residual } \\
\text { aqueous }\end{array}$ & $\begin{array}{l}\text { (i) TLC } \\
\text { (ii) HPLC }\end{array}$ & $\begin{array}{l}\text { (i) The retention factor of orientin is } \\
0.52 \text { for TLC analysis } \\
\text { (ii) Solve the problem of } \\
\text { overlapping of the isomers (orientin } \\
\text { and homorientin) chromatographic } \\
\text { bands in HPLC }\end{array}$ & {$[30-33]$} \\
\hline
\end{tabular}

[22]. In addition, Zhou et al. successfully isolated $95.8 \mathrm{mg}$ of orientin from $500 \mathrm{mg}$ of the crude extract of Trollius ledebouri with high-speed countercurrent chromatography (HSCCC) and semipreparative HPLC methods [23]. An ultraperformance liquid chromatography-electrospray ionization tandem mass spectrometric (UPLC-ESI-MS/MS) method has been developed by $\mathrm{Li}$ et al. in order to study the active compounds in Trollius ledebouri flower qualitatively and quantitatively. It was found that the smallest quantity of orientin that could be measured by this method was $515 \mu \mathrm{g}$ per gram of plant material [24].

Jatropha gossypifolia from Euphorbiaceae family is a tall shrub with plentiful fascicled bristles, originally from Brazil, but now can be found in all parts of India. The different parts of the plant are believed to have different medicinal values. For instance, the leaves are used as an insecticidal and wounds or ulcer healing agent, and the roots together with the leaves are used to treat anaemia, dysentery, fistula, and biliousness, while the seeds are used as aphrodisiacs, laxatives, and anthelmintic agents [40]. The seed oil is also a traditional medication for skin diseases such as itch, eczema, and herpes [40]. Orientin was isolated from the dried leaves of J. gossypifolia with the retention factor of 0.52 in TLC analysis [25-27]. Besides that, Pilon et al. used the crude leaf extracts of J. gossypifolia to improve the chromatographic resolution of HPLC-UV-diode-array detector (DAD) experiments to resolve the overlapping problem of chromatographic bands in HPLC between orientin and its isomer, homorientin [28].

Apart from the few plants mentioned above, there are some other medicinal plants that also contain orientin and yet are not as well studied. Orientin in the leaves and stems of Linum usitatissimum (flax) was first isolated together with some other compounds such as isoorientin, vitexin, isovitexin, vicenin-1, and vicenin-2 [29]. The natural herb that is used to treat type 2 diabetes, Commelina communis (dayflower), was found to contain orientin as well. The in vitro studies show that orientin has been one of the major antioxidants in this plant [30]. In addition, Gallori et al. have identified the presence of orientin in Euterpe oleracea Mart. (Acai palm) fruit by using HPLC-DAD-UV-Vis and HPLCMS analysis [31]. Soltis and Bohm also successfully obtained orientin and some other flavonoids from the methanol extract of Ascarina lucida leaves [32]. Besides that, orientin was also isolated from Celtis africana (white stinkwood) [33], Croton zambesicus (Lavender croton) leaves [34], Cajanus cajan (Pigeon pea) leaves [35], and Thlaspi arvense (Field Pennycress) [36].

Table 1 summarises the extraction methods and amount of orientin extracted in each main medicinal plant discussed above.

\section{Medicinal Properties of Orientin}

4.1. Antioxidant and Antiaging. Orientin has been widely studied for its antioxidant property. The antioxidant property of orientin can be explained through the study of its electron affinity, electronegativity, electrophilic index, and adiabatic ionization potential of its high radical scavenging activity which is the ability to donate electrons [41]. The effect of orientin on hydrogen peroxide- $\left(\mathrm{H}_{2} \mathrm{O}_{2}-\right)$ induced 
$\beta$-galactosidase activity also shows the antioxidant property of orientin. Orientin reduced the $\mathrm{H}_{2} \mathrm{O}_{2}$-induced $\beta$ galactosidase activity when compared to the increase of enzyme activity in $\mathrm{H}_{2} \mathrm{O}_{2}$ treatment alone [42]. Besides that, orientin significantly enhanced the survival of Escherichia coli mutants, DSH56 and DSH19 [42]. Nayak et al. also stated that the treatment of orientin highly reduced the mortality of the mutant cells, which is due to oxidation of macromolecules [42].

The antioxidant activity of orientin has also been shown in animal models. The D-galactose-treated aged mice were administrated with orientin for 8 weeks. An et al. found that orientin significantly increased the mice brain weights and general health status. The orientin-treated age mice also have increased levels of catalase, glutathione peroxidase, superoxide dismutase in serum, brain, liver, and kidneys, while the levels of malondialdehyde (a biomarker of oxidative stress) in the brain, liver, and kidneys as well as the levels of lipofuscin (an age pigment) were significantly decreased [43]. In addition, orientin also improves the structure of neuronal cell injuries in D-galactose-aged mice [43].

4.2. Antiviral and Antibacterial. The antiviral and antibacterial activities of orientin are beneficial for the future antibiotics development. Lin et al. [44] and Li et al. [45] have demonstrated that orientin has moderate or potent antiviral activity against Para 3 virus. Besides that, the flavonoids mixture (orientin, rutin, quercetin, and kaempferol) at the maximum nontoxic dose of $0.048 \mu \mathrm{g} / \mathrm{mL}$ fully inhibited Herpes Simplex Virus Type 2 (HSV-2) of different viral titre $\left(1,10,100 \mathrm{TCID}_{50}\right)$ on Hep-2 cells [46]. This is a great breakthrough in the medical field as HSV infection has been known to be a life-threatening disease. Apart from antiviral effects, orientin also expresses antibacterial effects. The study shows that the combination of flavonoids from Ocimum sanctum, orientin and vicenin, synergistically inhibited the growth of Escherichia coli, Staphylococcus aureus, Staphylococcus cohnii, Klebsiella pneumoniae, and Proteus, while the individual flavonoids were found to be less effective than the combined flavonoids [47]. The total flavonoids of Trollius chinensis include orientin and vitexin also showed evidence of antibacterial [44].

4.3. Anti-Inflammatory. Inflammation is a biological defence mechanism of tissue to injury or infection. Inflammation is characterized into acute and chronic phase in which they are differentiated by the presence of neutrophilic and monocytic leucocytes during the acute phase, whereas there are incidences of macrophages and lymphocytes during the chronic phase $[48,49]$. It is well studied that the development of atherosclerosis is strongly related to vascular inflammation; therefore, there is an urge to develop an anti-inflammation medication which benefits vascular inflammation [50]. The biomarkers of vascular inflammation, high mobility group box-1 (HMGB1) protein, and endothelial cell protein C receptor (EPCR) have been investigated after the treatment of orientin. Orientin has been shown to inhibit the HMGB1 level in lipopolysaccharide- (LPS-) induced umbilical vein endothelial cells (HUVECs) as well as the HMGB1-mediated cytoskeletal rearrangements [51]. In addition, in the human endothelial cell lines, orientin suppressed LPS-induced membrane disruption, migration of monocytes, expression of cell adhesion molecules (CAMs), and LPS-induced EPCR detaching [52]. Furthermore, in vivo assessments showed that orientin inhibited HMGB1-mediated and LPS-induced hyperpermeability, CLP-induced release of HMGB1 level, leukocyte migration, LPS-induced tumour necrosis factor- $\alpha$ (TNF- $\alpha$ ) level, interleukin-6 (IL-6) level, nuclear factor- $\kappa \mathrm{B}$ (NF- $\kappa$ B) level, extracellular regulated kinases (ERK) 1/2 level, and lethality of mice [52]. Besides that, diabetes mellitus is the main complication in the progression of atherosclerosis by vascular inflammation. Ku et al. have also found that pretreatment of orientin inhibited the high glucose-induced CAMs, reactive oxygen species (ROS), and NF- $\kappa$ B levels in HUVECs and mice [53].

4.4. Vasodilatation and Cardioprotective Effect. Presently, one of the most frequent cardiovascular diseases is hypertension, which increases the risk factor for congestive heart failure. Nevertheless, the maximum efficacy of the antihypertensive drugs is only $60 \%$ and typically two or more drugs from the categories of diuretics, calcium channel blockers, angiotensin converting enzyme or receptor blockers, adrenergic drugs, and vasodilators have to be combined to attain high efficacy on patients [54]. Therefore, vasorelaxant is an essential medication for hypertensive patients to reduce their elevated blood pressure and to protect the patients from cardiovascular diseases [54, 55].

Orientin has been identified to have vasodilatation effects on removed thoracic aortic rings from the New Zealand rabbit. It was found that orientin with an $\mathrm{IC}_{50}$ value of $2.28 \mu \mathrm{M}$ and $7.27 \mu \mathrm{M}$ relaxed phenylephrine-induced contractions in the endothelium-intact and endothelium-isolated aortic rings, respectively [56]. The possible pathway that orientin acts as a vasorelaxant on thoracic aortic rings is by the nitricoxide-cGMP pathway, while in the vascular smooth muscle, it relaxes the muscle via activation of voltage-dependent calcium channels [56].

Besides that, orientin has been massively studied for its in vivo cardioprotective effect. Orientin was demonstrated to reduce myocardium apoptosis of rat heart with ischemiareperfusion. The apoptosis of rat cardiomyocytes that were injured by hypoxia/reoxygenation also decreased upon pretreatment with orientin at 3,10 , and $30 \mu \mathrm{mol} \mathrm{L}^{-1}$ [57]. Studies also showed that the protein levels of Bax, cytochrome c, and caspase- 3 were reduced, whereas the level of bcl- 2 was increased. This shows that orientin has antiapoptotic effect on ischemia-reperfusion and hypoxia/reoxygenation-treated heart and cardiomyocytes by deactivating the cytochrome c-caspase-3 mitochondrial apoptotic pathway [57]. On the other hand, Liu et al. showed that the myocardial structures, ventricular remodeling, electrocardiogram, and hemodynamic index of myocardial infarction rats have been improved after the treatment of orientin [58].

In addition, the cardioprotective effect of orientin has also been shown in dogs. Orientin increased endogenous 
antioxidase activity and reduced the oxygen-free radical formation by inhibiting the serum creatine phosphokinase and lactic dehydrogenase activities as well as enhancing superoxide dismutase activity in acute myocardial infarction dogs while reducing the myocardial infarction sizes [59]. In addition, the cardiac function upon orientin treatment has been observed in anesthetized open-chest dogs. Results showed that orientin was able to diminish maximal rising or dropping rate of intraventricular pressure $\left( \pm d p / d t_{\max }\right)$ and left ventricular end dilation pressure and myocardial oxygen consumption but enhance cardiac output and coronary blood flow to boost up cardiac function in anesthetized dogs [60]. Moreover, orientin has been revealed to reduce arachidonic acid-induced blood platelet aggregation in rabbits and improve coronal flow in the removed heart of guinea pigs [61]. However, the in vitro study on the cardioprotective effect of orientin demonstrated the repolarization of mitochondrial membrane potential, reduced generation of reactive oxygen species, inhibition of mitochondrial cytochrome c, and the association with the PI3K/Akt signaling pathway by orientin on the H9c2 cardiomyocytes cells [62].

4.5. Radioprotective Effect. The radiation protective compounds have been widely studied recently due to the highly damaging power of ionizing radiation on human tissues. The damage of DNA and proteins by radiation can result in apoptosis, necrosis, mitotic death, or cell cycle interruption on the normal tissues [63]. Therefore, the search of radioprotective compounds is vital to protect human against radiation. Two flavonoids isolated from the leaves of Ocimum sanctum, orientin and vicenin, have been frequently examined for their radioprotective effect. The pretreatment of optimal dose at $50 \mu \mathrm{g} / \mathrm{kg}$ body weight of orientin or vicenin 30 minutes on mice before being exposed to $11 \mathrm{~Gy}$ of gamma radiation showed protection against fatality, but the posttreatment of orientin or vicenin was not as effective as pretreatment [11]. The possible mechanisms of action of this protective effect were then determined. Both flavonoids have given protection against whole-body 3 Gy of gamma radiation-induced lipid peroxidation in mouse liver and also scavenged free radical activities include diphenylpicrylhydrazyl (DPPH) and $2,2^{\prime}$ azino-bis(3-ethylbenzothiazoline-6-sulfonic acid) (ABTS) in vitro [64]. Therefore, the antioxidant activity of the flavonoids might be the possible pathway of the radiation protective effect.

Additionally, in the Micronucleus (MN) assay, the treatment of orientin or vicenin at the optimum concentration of $17.5 \mu \mathrm{M}$ decreased the radiation-induced $\mathrm{MN}$ frequency, which indicates reduced chromosome damage in the human peripheral lymphocytes [65]. Besides that, the radiation protective effect of orientin and vicenin was demonstrated in mouse bone marrow as well. The intraperitoneal injection of orientin or vicenin significantly diminished the radiationinduced chromosomal aberrant cells and enhanced the number of exogenous spleen colonies (CFU-S) [66]. The ex vivo irradiated mouse splenocytes also showed a faster repairing effect and less radiation-induced DNA damage by orientin or vicenin [67]. The clonogenic survival of repair proficient cells was also elevated [9]. Furthermore, the combination treatment of orientin and vicenin together with two synthetic compounds WR-2721 and 2-mercaptopropionyl glycine (MPG) demonstrated reduced chromosomal aberration cells in bone marrow and significant drop in the percentage of aberrant metaphases [67]. These studies propose the potential of orientin and vicenin in protecting the normal tissues during the radiotherapy in cancer patients and the protection of radiation-related job workers such as radiologists.

4.6. Neuroprotective or Antidepressant-Like Effect. Neurodegenerative diseases are the incurable and weakening conditions where there are aggregation and deposition of misfolded intracellular and extracellular proteins, which lead to progressive central nervous system diseases $[68,69]$. They have been emphasised among aging diseases because of the inadequate effective treatment, incurability, and associated economic and social burdens [70]. Therefore, there is an urge for the development of preventive or curative neuroprotective medications for the patients. A previous study using 3(4,5-dimethylthiazol-2-yl)-2,5-diphenyltetrazolium bromide (MTT) assay reported that orientin at the concentration of less than $20 \mu \mathrm{M}$ was not cytotoxic to SH-SY5Y neuroblastoma cells [71]. In this study, the percentage of apoptotic cells was significantly decreased compared to the cells treated with $150 \mu \mathrm{M} \mathrm{H}_{2} \mathrm{O}_{2}$ alone. Law et al. concluded that this antiapoptotic effect of orientin could have been attributed to the inactivation of caspases $3 / 7$ and caspase- 9 activities based on the caspase assays [71].

The neuroprotective effect has also been demonstrated in Amyloid $\beta$-Protein- $\left(\mathrm{A} \beta_{1-42^{-}}\right)$induced mitochondrial dysfunction oxidative-stressed (Alzheimer's disease, $\mathrm{AD}$ ) mice. Orientin was found to improve cognitive impairment of the AD mice and significantly reduced the levels of the oxidative stress biomarkers: 3-nitrotyrosine (3-NT), 4-hydroxynonenal (4-HNE), 8-hydroxy-2' -deoxyguanosine (8-OHdG), and ROS [72]. The mitochondrial apoptotic pathway was attenuated by reducing mitochondrial dysfunction by orientin. The possible pathway that orientin protects $\mathrm{AD}$ mice was found to be $\mathrm{Nrf} 2 / \mathrm{HO}-1$ redox signaling pathway as the expression of HO-1 was increased during the study [72].

Besides that, orientin also showed antidepressant-like effect. The chronic unpredictable mild stress (CUMS) mice showed enhanced central oxidative stress, amplified serotonin, and norepinephrine levels as well as less CUMSinduced depression-like behaviours upon oral treatment of orientin for 3 weeks [73].

4.7. Antiadipogenesis Effects. Adipogenesis is the process by which undifferentiated precursor cells differentiate into fat cells and further leads to the increasing prevalence of obesity among the society. Orientin together with some other flavonoids has been reported to exhibit potent antiadipogenesis activity. The orientin isolated from the ethanol extract of Spirodela polyrhiza exerts antiadipogenesis on lipid accumulation in 3T3-L1 cells [74]. In this study, Kim et al. discovered that the butanol soluble fraction had the highest adipogenesis and intracellular triglyceride accumulation 
inhibitory effect, by inhibiting the protein expressions of $\mathrm{C} / \mathrm{EBP} \alpha$ and PPAR $\gamma$ [74]. C/EBP $\alpha$ and PPAR $\gamma$ are the essential transcription factors during adipogenesis and participate in a single pathway of fat cell development with PPAR being the proximal effector of adipogenesis [75]. Considering the antiadipogenesis mechanism of orientin, it could be one of the useful therapeutic agents for obesity and type 2 diabetes patients.

4.8. Antinociceptive Effects. Pain is one of the most frequently observed symptoms of different pathologies. The principal targets of effective pain management are to ameliorate nociception, to reduce the threshold of pain sensation, and to improve quality of life [76]. The pain relieved effect of orientin has been demonstrated in models of pain in mice. Orientin with the $\mathrm{ID}_{50}$ of $6.5 \mathrm{mg} / \mathrm{kg}$ was able to reduce acetic acidinduced writhing and capsaicin- and glutamate-induced pain in mice [77]. Surprisingly, Da Silva et al. also discovered that orientin was 20-fold more potent than the typical painkiller, acetylsalicylic acid (aspirin), and 3.5-fold more dynamic than the common anti-inflammatory drug, indomethacin [77]. Thus, orientin can be an alternative antinociceptive treatment to the patients.

\section{Concluding Remarks}

The extensive studies of orientin on the medicinal properties of antioxidant, antiaging, antiviral, anti-inflammation, vasodilatation and cardioprotective, radioprotective, neuroprotective, antiadipogenesis, and antinociceptive effects can lead to promising therapeutic effect of orientin in the medical field. Yet the underlying mechanisms of these therapeutic properties are not well studied and remain indecisive. Besides that, orientin was found to have difficulty in crossing the blood-brain-barrier due to its hydrophilicity [78]. In addition, at this stage, most of the biological studies of orientin comprise only in vitro and preclinical investigations. Clinical data are yet to be available to support the use of orientin in patients. Therefore, the future research on orientin should be focused on the underlying pathways, the pharmacokinetics, and the tissue distribution in the human body in order to develop a highly effective drug which causes less adverse effects to patients.
Abbreviations
AOB:
HPLC:
Antioxidant of bamboo leaves
TLC: Thin-layer chromatography
UPLC-ESI-MS/MS: Ultraperformance liquid
chromatography-electrospray
ionization tandem mass
spectrometric
HSCCC:
High-speed countercurrent
chromatography
$\mathrm{H}_{2} \mathrm{O}_{2}$ :
HSV-2:

$\mathrm{TCID}_{50}$ : Median tissue culture infective dose

HMGB1: Mobility group box-1

EPCR: Endothelial cell protein $\mathrm{C}$ receptor

LPS: Lipopolysaccharide

HUVECs: Umbilical vein endothelial cells

CAMs: Cell adhesion molecules

TNF- $\alpha$ : Tumour necrosis factor- $\alpha$

IL-6: Interleukin-6

NF- $\kappa$ B: $\quad$ Nuclear factor $-\kappa \mathrm{B}$

ERK: $\quad$ Extracellular regulated kinases

ROS: $\quad$ Reactive oxygen species

$\mathrm{IC}_{50}$ : Half maximal inhibitory concentration

DPPH: Diphenylpicrylhydrazyl

ABTS: $\quad 2,2^{\prime}$-azino-bis(3-ethylbenzothiazoline-6sulfonic acid)

MN: Micronucleus

CFU-S: Exogenous spleen colony

MPG: 2-Mercaptopropionyl glycine

MTT: 3- (4, 5-Dimethylthiazol-2-yl)-2,5-diphen-

A $\beta$ : $\quad$ Amyloid $\beta$-Protein

CUMS: Chronic unpredictable mild stress

$\mathrm{ID}_{50}$ : Half maximal inhibitory dose.

\section{Competing Interests}

The authors declare that there is no conflict of interests regarding the publication of this paper.

\section{Acknowledgments}

The study is funded by the Ministry of Higher Education, Malaysia, under the Fundamental Research Grant Scheme (FRGS) (FRGS/1/2013/SKK07/IMU/03/3). Acknowledgment is due to Henry Ling of Columbia University, New York, for his editorial comments.

\section{References}

[1] R. Solecki, "Shanidar IV, a neanderthal flower burial in northern Iraq," Science, vol. 190, no. 4217, pp. 880-881, 1975.

[2] I. A. Ross, Medicinal Plants of the World, Volume 3: Chemical Constituents, Traditional and Modern Medicinal Uses, Humana Press, 2005.

[3] I. A. Ross, Medicinal Plants of the World, Volume 1: Chemical Constituents, Traditional and Modern Medicinal Uses, Humana Press, 2003.

[4] P. Pattanayak, P. Behera, D. Das, and S. K. Panda, "Ocimum sanctum Linn. A reservoir plant for therapeutic applications: an overview," Pharmacognosy Reviews, vol. 4, no. 7, pp. 95-105, 2010.

[5] S. K. Das and D. M. Vasudevan, "Tulsi: the Indian holy power plant," Indian Journal of Natural Products and Resources, vol. 5, no. 4, pp. 279-283, 2006.

[6] S. M. K. Rates, "Plants as source of drugs", Toxicon, vol. 39, no. 5, pp. 603-613, 2001.

[7] D. S. Fabricant and N. R. Farnsworth, "The value of plants used in traditional medicine for drug discovery," Environmental Health Perspectives, vol. 109, supplement 1, pp. 69-75, 2001. 
[8] S. Prasad and A. K. Tyagi, "Traditional medicine: the goldmine for modern drugs," Advanced Techniques in Biology \& Medicine, vol. 3, no. 1, article 1, 2015.

[9] M. Satyamitra, S. Mantena, C. K. K. Nair et al., "The antioxidant flavonoids, orientin and vicenin enhance repair of radiationinduced damage," Scholarena Journal of Pharmacy and Pharmacology, vol. 1, no. 1, article 105, 2014.

[10] A. G. R. Nair, R. Gunasegaran, and S. Joshi, "Chemical investigation of some South Indian plants," Indian Journal of Chemistry $B$, vol. 21, p. 979, 1982.

[11] P. Uma Devi, A. Ganasoundari, B. S. S. Rao, and K. K. Srinivasan, "In Vivo radioprotection by Ocimum flavonoids: survival of mice," Radiation Research, vol. 151, no. 1, pp. 74-78, 1999.

[12] Y.-X. Zhang and C.-H. He, "Process for extracting and separating total flavonoids from leaves of phyllostachys pubescens," Journal of Chemical Engineering of Chinese Universities, vol. 20, no. 5, pp. 690-695, 2006.

[13] B. Y. Lu, X. Q. Wu, J. Y. Shi, Y. J. Dong, and Y. Zhang, "Toxicology and safety of antioxidant of bamboo leaves. Part 2: developmental toxicity test in rats with antioxidant of bamboo leaves," Food and Chemical Toxicology, vol. 44, no. 10, pp. 1739$1743,2006$.

[14] W. X. Sun, X. Li, N. Li, and D. L. Meng, "Chemical constituents of the extraction of bamboo leaves from Phyllostachys nigra (Loddex Lindl) Munro varhenonis (Mitf) Stepfex Rendle," Journal of Shenyang Pharmaceutical University, vol. 25, no. 1, pp. 39-43, 2008.

[15] J. Xie, P. P. Zhou, X. Y. Zhu, X. J. Liu, R. E. Chen, and P. Wang, "Study on extraction of bamboo leaves flavonoids by homogenate extraction technique and its antioxidant activity," Food Science and Technology, vol. 2010, no. 5, pp. 194-198, 2010.

[16] C. J. Yong, L. L. Hua, and Y. Ke, "Simultaneous determination of seven effective constituents in the leaves of bamboo by reversed phase high performance liquid chromatography (RP-HPLC)," Journal of Medicinal Plant Research, vol. 5, no. 23, pp. 56305635, 2011.

[17] Y. Zhang, J. Jiao, C. Liu, X. Wu, and Y. Zhang, "Isolation and purification of four flavone $C$-glycosides from antioxidant of bamboo leaves by macroporous resin column chromatography and preparative high-performance liquid chromatography," Food Chemistry, vol. 107, no. 3, pp. 1326-1336, 2008.

[18] J. Sun, Y. Yue, F. Tang, and X. Guo, "Simultaneous HPTLC analysis of flavonoids in the leaves of three different species of bamboo," Journal of Planar Chromatography-Modern TLC, vol. 23, no. 1, pp. 40-45, 2010.

[19] O. Grundmann, J. Wang, G. P. McGregor, and V. Butterweck, "Anxiolytic activity of a phytochemically characterized Passiflora incarnata extract is mediated via the GABAergic system," Planta Medica, vol. 74, no. 15, pp. 1769-1773, 2008.

[20] F. de Paris, R. D. Petry, F. H. Reginatto et al., "Pharmacochemical study of aqueous extracts of Passiflora alata Dryander and Passiflora edulis Sims," Acta Farmaceutica Bonaerense, vol. 21, no. 1, pp. 5-8, 2002.

[21] Z. Liu, L. Wang, W. Li, Y. Huang, and Z.-C. Xu, "Determination of orientin and vitexin in Trollius chinesis preparation by HPLC," China Journal of Chinese Materia Medica, vol. 29, no. 11, pp. 1049-1051, 2004.

[22] L.-Z. Wu, H.-F. Wu, X.-D. Xu, and J.-S. Yang, “Two new flavone C-glycosides from Trollius ledebouri," Chemical and Pharmaceutical Bulletin, vol. 59, no. 11, pp. 1393-1395, 2011.
[23] X. Zhou, J. Y. Peng, G. R. Fan, and Y. T. Wu, "Isolation and purification of flavonoid glycosides from Trollius ledebouri using high-speed counter-current chromatography by stepwise increasing the flow-rate of the mobile phase," Journal of Chromatography A, vol. 1092, no. 2, pp. 216-221, 2005.

[24] X. Li, Z. Xiong, X. Ying, L. Cui, W. Zhu, and F. Li, "A rapid ultraperformance liquid chromatography-electrospray ionization tandem mass spectrometric method for the qualitative and quantitative analysis of the constituents of the flower of Trollius ledibouri Reichb," Analytica Chimica Acta, vol. 580, no. 2, pp. 170-180, 2006.

[25] J. Félix-Silva, T. Souza, Y. A. S. Menezes et al., "Aqueous leaf extract of Jatropha gossypiifolia L. (Euphorbiaceae) inhibits enzymatic and biological actions of Bothrops jararaca snake venom," PLoS ONE, vol. 9, no. 8, Article ID e104952, 2014.

[26] J. Félix-Silva, T. Souza, R. B. A. G. Camara et al., "In vitro anticoagulant and antioxidant activities of Jatropha gossypiifolia L. (Euphorbiaceae) leaves aiming therapeutical applications," BMC Complementary and Alternative Medicine, vol. 14, article 405, 2014.

[27] J. Félix-Silva, J. A. S. Gomes, L. M. De Quadros Barbosa et al., "Systemic and local anti-inflammatory activity of aqueous leaf extract from Jatropha gossypiifolia L. (Euphorbiaceae)," International Journal of Pharmacy and Pharmaceutical Sciences, vol. 6, no. 6, pp. 142-145, 2014.

[28] A. C. Pilon, R. L. Carneiro, F. S. Carnevale Neto, V. Bolzani, and I. Castro-Gamboa, "Interval multivariate curve resolution in the dereplication of HPLC-DAD data from Jatropha gossypifolia," Phytochemical Analysis, vol. 24, no. 4, pp. 401-406, 2013.

[29] J. Dubois and T. J. Mabry, "The C-glycosylflavonoids of flax, Linum usitatissimum," Phytochemistry, vol. 10, no. 11, pp. 28392840, 1971.

[30] M. Shibano, K. Kakutani, M. Taniguchi, M. Yasuda, and K. Baba, "Antioxidant constituents in the dayflower (Commelina communis L.) and their $\alpha$-glucosidase-inhibitory activity," Journal of Natural Medicines, vol. 62, no. 3, pp. 349-353, 2008.

[31] S. Gallori, A. R. Bilia, M. C. Bergonzi, W. L. R. Barbosa, and F. F. Vincieri, "Polyphenolic constituents of fruit pulp of Euterpe oleracea Mart. (Açai palm)," Chromatographia, vol. 59, no. 11-12, pp. 739-743, 2004.

[32] D. E. Soltis and B. A. Bohm, "Flavonoids of Ascarina lucida," Journal of Natural Products, vol. 45, no. 4, pp. 415-417, 1982.

[33] S. Perveen, A. M. El-Shafae, A. Al-Taweel et al., "Antioxidant and urease inhibitory $C$-glycosylflavonoids from Celtis africana," Journal of Asian Natural Products Research, vol. 13, no. 9, pp. 799-804, 2011.

[34] H. Wagner, L. Hörhammer, and I. C. Kiraly, "Flavon-c-glykoside in Croton zambezicus," Phytochemistry, vol. 9, no. 4, p. 897, 1970.

[35] D. Pal, P. Mishra, N. Sachan, and A. K. Ghosh, "Biological activities and medicinal properties of Cajanus cajan (L) Millsp.", Journal of Advanced Pharmaceutical Technology and Research, vol. 2, no. 4, pp. 207-214, 2011.

[36] S. Pang, Y. Ge, L. S. Wang, X. Liu, C. W. Lin, and H. Yang, "Isolation and purification of orientin and isovitexin from Thlaspi arvense linn," Advanced Materials Research, vol. 781784, pp. 615-618, 2013.

[37] R.-F. Wang, X.-W. Yang, C.-M. Ma et al., "Trollioside, a new compound from the flowers of Trollius chinensis," Journal of Asian Natural Products Research, vol. 6, no. 2, pp. 139-144, 2004.

[38] B. Koeppen and D. Roux, "C-gylcosylflavonoids: the chemistry of orientin and iso-orientin," Biochemical Journal, vol. 97, no. 2, pp. 444-448, 1965. 
[39] P. Uma Devi, "Radioprotective, anticarcinogenic and antioxidant properties of the Indian Holy Basil, Ocimum sanctum (Tulasi)," Indian Journal of Experimental Biology, vol. 39, no. 3, pp. 185-190, 2001.

[40] M. Daniel, Medicinal Plants: Chemistry and Properties, Science Publishers, 2006.

[41] R. Praveena, K. Sadasivam, V. Deepha, and R. Sivakumar, "Antioxidant potential of orientin: a combined experimental and DFT approach," Journal of Molecular Structure, vol. 1061, no. 1, pp. 114-123, 2014.

[42] V. Nayak, H. Nishioka, and P. Uma Devi, "Antioxidant and radioprotective effects of Ocimum flavonoids orientin and vicenin in Escherichia coli," Defence Science Journal, vol. 56, no. 2, pp. 179-187, 2006.

[43] F. An, G. D. Yang, J. M. Tian, and S. H. Wang, "Antioxidant effects of the orientin and vitexin in Trollius chinensis Bunge in D-galactose-aged mice," Neural Regeneration Research, vol. 7, no. 33, pp. 2565-2575, 2012.

[44] Q. F. Lin, S. Q. Feng, Y. Z. Cen, Y. T. Yang, and L. Y. Wang, "Study on the antibacterial and antiviral activity compositions of Trollium chinensis Bunge," Journal of Zhejiang University SCIENCE B, vol. 31, no. 4, pp. 412-415, 2004.

[45] Y.-L. Li, S.-C. Ma, Y.-T. Yang, S.-M. Ye, and P. P.-H. But, "Antiviral activities of flavonoids and organic acid from Trollius chinensis Bunge," Journal of Ethnopharmacology, vol. 79, no. 3, pp. 365-368, 2002.

[46] S. P. Boominathan, G. Sarangan, S. Srikakelapu, S. Rajesh, C. Duraipandian, and P. Srikanth, "Antiviral activity of bioassay guided fractionation of Plumbago zeylanica roots against Herpes Simplex Virus Type 2," World Journal of Pharmaceutical Sciences, vol. 3, no. 12, pp. 1003-1017, 2014.

[47] H. Ali and S. Dixit, "In vitro antimicrobial activity of flavanoids of Ocimum sanctum with synergistic effect of their combined form," Asian Pacific Journal of Tropical Disease, vol. 2, no. 1, pp. S396-S398, 2012.

[48] C. A. Feghali and T. M. Wright, "Cytokines in acute and chronic inflammation," Frontiers in Bioscience, vol. 2, pp. d12-d26, 1997.

[49] C. Gabay, "Interleukin-6 and chronic inflammation," Arthritis Research and Therapy, vol. 8, supplement 2, p. S3, 2006.

[50] A. R. Brasier, A. Recinos III, M. S. Eledrisi, and M. S. Runge, "Vascular inflammation and the renin-angiotensin system," Arteriosclerosis, Thrombosis, and Vascular Biology, vol. 22, no. 8, pp. 1257-1266, 2002.

[51] H. Y. Yoo, S.-K. Ku, T. H. Lee, and J.-S. Bae, "Orientin inhibits HMGB1-induced inflammatory responses in HUVECs and in murine polymicrobial sepsis," Inflammation, vol. 37, no. 5, pp. 1705-1717, 2014.

[52] W. H. Lee, S.-K. Ku, and J.-S. Bae, "Vascular barrier protective effects of orientin and isoorientin in LPS-induced inflammation in vitro and in vivo," Vascular Pharmacology, vol. 62, no. 1, pp. 3-14, 2014.

[53] S.-K. Ku, S. Y. Kwak, and J.-S. Bae, "Orientin inhibits high glucose-induced vascular inflammation in vitro and in vivo," Inflammation, vol. 37, no. 6, pp. 2164-2173, 2014.

[54] T. Sun, R. Liu, and Y.-X. Cao, "Vasorelaxant and antihypertensive effects of formononetin through endothelium-dependent and -independent mechanisms," Acta Pharmacologica Sinica, vol. 32, no. 8, pp. 1009-1018, 2011.

[55] T. Ogihara, M. Matsuzaki, H. Matsuoka et al., "The combination therapy of hypertension to prevent cardiovascular events (COPE) trial: rationale and design," Hypertension Research, vol. 28, pp. 331-338, 2005.
[56] X.-C. Fu, M.-W. Wang, S.-P. Li, Y. Zhang, and H.-L. Wang, "Vasodilatation produced by orientin and its mechanism study," Biological and Pharmaceutical Bulletin, vol. 28, no. 1, pp. 37-41, 2005.

[57] X.-C. Fu, M.-W. Wang, S.-P. Li, and H.-L. Wang, "Anti-apoptotic effect and the mechanism of orientin on ischaemic/reperfused myocardium," Journal of Asian Natural Products Research, vol. 8, no. 3, pp. 265-272, 2006.

[58] L. Y. Liu, Q. Q. Ma, J. Y. Li et al., "The therapeutic effect of orientin on myocardial infarction rats," Lishizhen Medicine and Materia Medica Research, vol. 2013, no. 8, pp. 1807-1810, 2013.

[59] X. C. Fu, Z. X. Huang, Y. W. Cai, and Q. H. Yang, "Protective effects of orientin on experimental myocardial infarction in dogs," Herald of Medicine, vol. 25, no. 7, pp. 621-623, 2006.

[60] X. C. Fu, Q. H. Yang, Z. X. Huang, and S. P. Li, "Effects of orientin on cardiac function and hemodynamics in anesthetized dogs," West China Journal of Pharmaceutical Sciences, vol. 22, no. 3, pp. 289-291, 2007.

[61] X.-C. Fu, X. Wang, H. Zheng, and L.-P. Ma, "Protective effects of orientin on myocardial ischemia and hypoxia in animal models," Journal of Southern Medical University, vol. 27, no. 8, pp. 1173-1175, 2007.

[62] N. Lu, Y. Sun, and X. Zheng, "Orientin-induced cardioprotection against reperfusion is associated with attenuation of mitochondrial permeability transition," Planta Medica, vol. 77, no. 10, pp. 984-991, 2011.

[63] C. K. K. Nair, D. K. Parida, and T. Nomura, "Radioprotectors in radiotherapy," Journal of Radiation Research, vol. 42, no. 1, pp. 21-37, 2001.

[64] P. Uma Devi, A. Ganasoundari, B. Vrinda, K. K. Srinivasan, and M. K. Unnikrishnan, "Radiation protection by the Ocimum flavonoids orientin and vicenin: mechanisms of action," Radiation Research, vol. 154, no. 4, pp. 455-460, 2000.

[65] B. Vrinda and P. Uma Devi, "Radiation protection of human lymphocyte chromosomes in vitro by orientin and vicenin," Mutation Research/Genetic Toxicology and Environmental Mutagenesis, vol. 498, no. 1-2, pp. 39-46, 2001.

[66] Nayak and P. Uma Devi, "Protection of mouse bone marrow against radiation-induced chromosome damage and stem cell death by the Ocimum flavonoids orientin and vicenin," Radiation Research, vol. 163, no. 2, pp. 165-171, 2005.

[67] P. Uma Devi, K. S. Bisht, and M. Vinitha, "A comparative study of radioprotection by Ocimum favonoids and synthetic aminothiol protectors in the mouse," British Journal of Radiology, vol. 71, no. 847, pp. 782-784, 1998.

[68] C. A. Ross and M. A. Poirier, "Protein aggregation and neurodegenerative disease," Nature Medicine, vol. 10, pp. S10-S17, 2004.

[69] D. M. Skovronsky, V. M.-Y. Lee, and J. Q. Trojanowski, "Neurodegenerative diseases: new concepts of pathogenesis and their therapeutic implications," Annual Review of Pathology, vol. 1, pp. 151-170, 2006.

[70] C.-W. Hung, Y.-C. Chen, W.-L. Hsieh, S.-H. Chiou, and C.-L. Kao, "Ageing and neurodegenerative diseases," Ageing Research Reviews, vol. 9, supplement, pp. S36-S46, 2010.

[71] B. N. T. Law, A. P. K. Ling, R. Y. Koh, S. M. Chye, and Y. P. Wong, "Neuroprotective effects of orientin on hydrogen peroxide-induced apoptosis in SH-SY5Y cells," Molecular Medicine Reports, vol. 9, no. 3, pp. 947-954, 2014.

[72] L. Yu, S. Wang, X. Chen et al., "Orientin alleviates cognitive deficits and oxidative stress in $\mathrm{A} \beta_{1-42}$-induced mouse model of Alzheimer's disease," Life Sciences, vol. 121, pp. 104-109, 2015. 
[73] Y. Liu, N. Lan, J. Ren et al., "Orientin improves depressionlike behavior and BDNF in chronic stressed mice," Molecular Nutrition \& Food Research, vol. 59, no. 6, pp. 1130-1142, 2015.

[74] J. Kim, I. Lee, J. Seo et al., "Vitexin, orientin and other flavonoids from Spirodela polyrhiza inhibit adipogenesis in 3T3-L1 cells," Phytotherapy Research, vol. 24, no. 10, pp. 1543-1548, 2010.

[75] E. D. Rosen, C.-H. Hsu, X. Wang et al., "C/EBP $\alpha$ induces adipogenesis through PPAR $\gamma$ : a unified pathway," Genes and Development, vol. 16, no. 1, pp. 22-26, 2002.

[76] F. S. Kilic, B. Sirmagul, E. Yildirim, S. Oner, and K. Erol, "Antinociceptive effects of gabapentin and its mechanism of action in experimental animal studies," Indian Journal of Medical Research, vol. 135, no. 5, pp. 630-635, 2012.

[77] R. Z. Da Silva, R. A. Yunes, M. M. De Souza, F. D. Monache, and V. Cechinel-Filho, "Antinociceptive properties of conocarpan and orientin obtained from Piper solmsianum C. DC. var. solmsianum (Piperaceae)," Journal of Natural Medicines, vol. 64, no. 4, pp. 402-408, 2010.

[78] D. Q. Li, Q. Wang, Z. F. Yuan et al., "Pharmacokinetics and tissue distribution study of orientin in rat by liquid chromatography," Journal of Pharmaceutical and Biomedical Analysis, vol. 47, no. 2, pp. 429-434, 2008. 

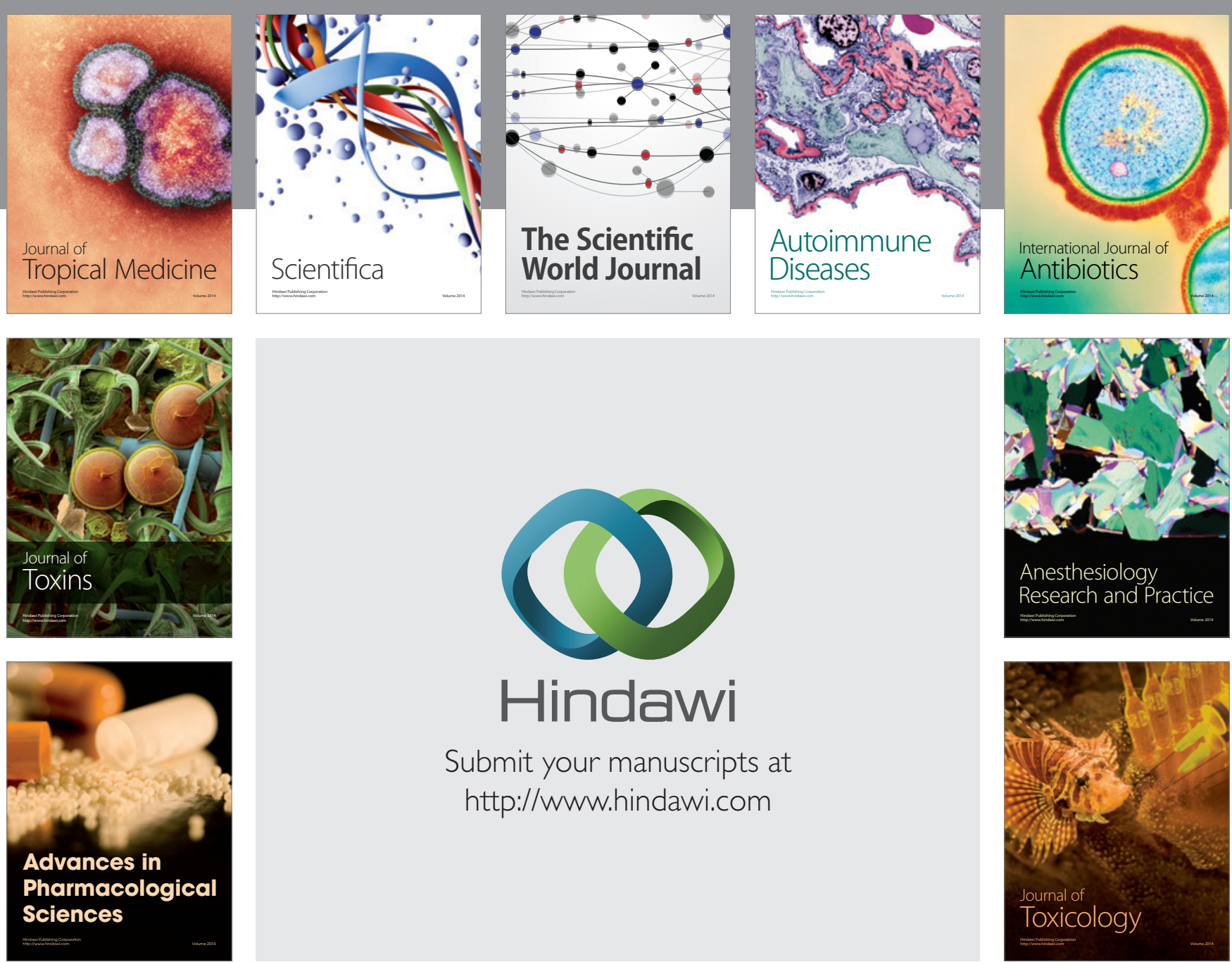

\section{Hindawi}

Submit your manuscripts at

http://www.hindawi.com
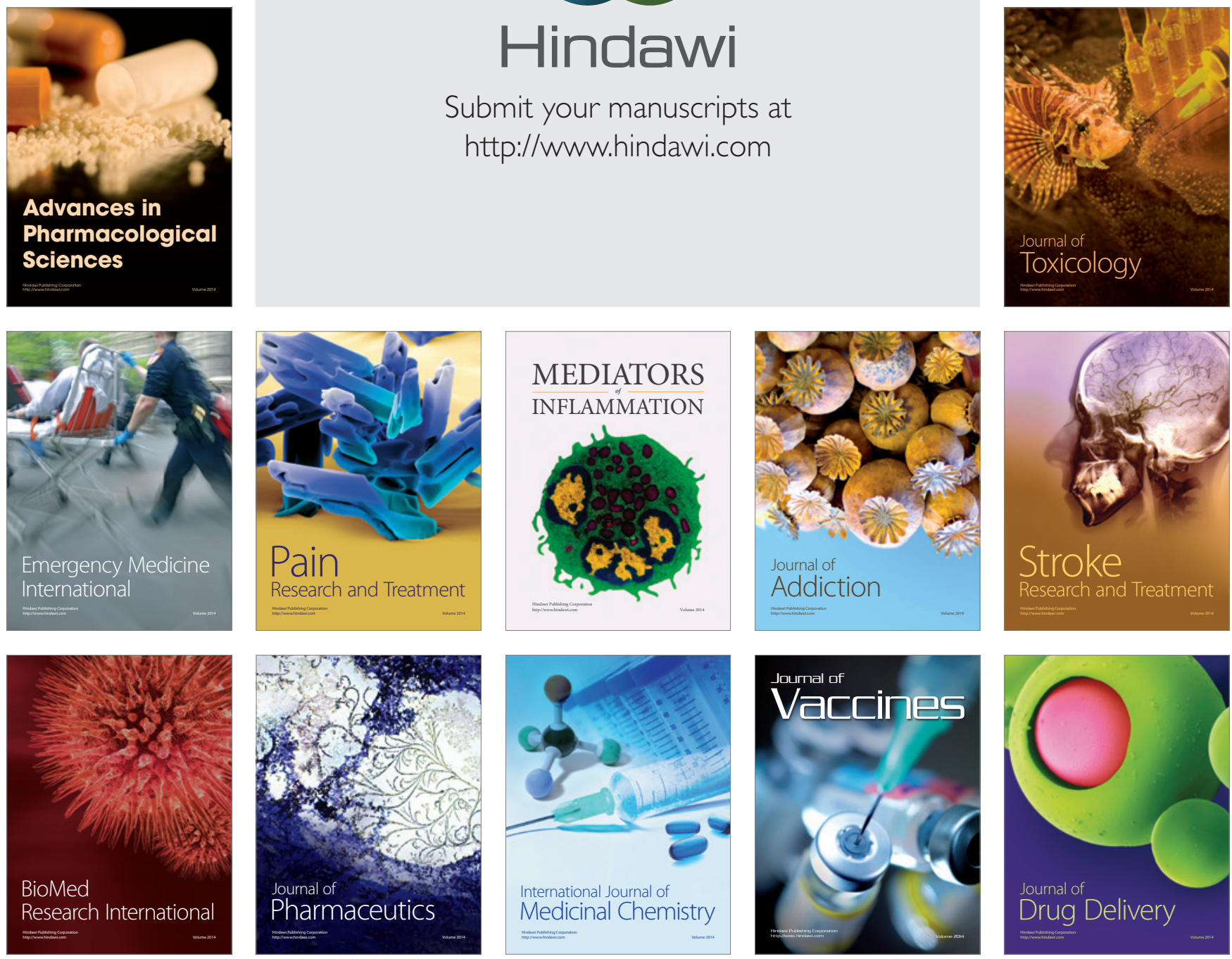